\title{
Effect of Fixed-Base and Soil Structure Interaction on the Dynamic Responses of Steel Structures
}

\author{
Halmat Ahmed Awlla ${ }^{1}$, Nichirvan Ramadhan Taher ${ }^{2}$, Yousif Ismael Mawlood ${ }^{3}$ \\ ${ }^{1}$ Department of Information Technology, Choman Technical Institute, Erbil Polytechnic University, Erbil, Iraq. \\ ${ }^{2}$ PhD Candidate, Department of Civil Engineering, Faculty of Engineering, Firat University, Elazig, Turkey. \\ ${ }^{3}$ Department of Civil Engineering, College of Engineering, Salahaddin University, Erbil, Iraq. \\ ${ }^{1}$ halmat.awlla@epu.edu.iq, ${ }^{2}$ taher.nichirvan@gmail.com, ${ }^{3}$ yousif.mawlood@ su.edu.krd
}

\begin{abstract}
To study soil-structure interaction (SSI) and create an exact computer model of soils, geotechnical and geological studies are necessary. Since these investigations are neglected for most projects for various reasons, engineers use the fixed base concept to analyze the structures. This study examines the accuracy and effect of fixed-base concept on the dynamic responses of steel structures. For this purpose, the dynamic responses in terms of base shear and top displacement of a four-story steel structure were studied by using SAP2000 finite element software.The structure rested on a big soil medium that was numerically modelled in a full $3 \mathrm{D}$ manner using solid finite elements, four different soil profiles in well-known seismic codes were defined (Rock, Very dense, Stiff and Soft soils). Provided information in the codes and the equations of the literature were utilized for numerical modeling. After performing finite element analysis, a comparison was made between the dynamic responses of the fixed base structure with structures rested on different types of the soil profile. According to the results of the analysis, it was observed that the base shear and the top displacement of the fixed base structure are almost the same with the structure resting on the rocky soil, but underestimated comparing to remaining soil profiles.
\end{abstract}

Key words: Dynamic loading, 3D numerical modeling, Soil profiles and Soil structure interaction.

\section{INTRODUCTION}

In most cases of engineering analysis and design, SSI is neglected. Alternatively, the base of the structures is considered to be fixed-base models, especially for preliminary proposals and in situations where there are no detailed geotechnical and geological reports. The properties of the structure, SSI and the characteristics of the movement of the ground have a considerable influence on the increasing or decreasing structural reaction to the ground motion due to the seismic load [1-3]. Tabatabaiefar et al. (2013) and Ghandil et al (2017) [2, 4] stated that to predict the actual structural response to seismic ground motion, the SSI must be taken into account. In the flexible soil environment, the acceleration of structures is strongly affected by SSI [2, 5]. Considerable damage noticed in regions with soft soil profile through (1985 Mexico city, 1989 Loma Prieta, 1994 Northridge and 1995 Kobe) earthquakes, damage to structures affected by these earthquakes discovered that SSI plays a crucial role in the response of structures to earthquake loads [6-8]. To take into account the impact of SSI, certain analytical methods have been developed from the above-mentioned earthquakes data and others recorded from instrumented sites, moreover, using the calibration of numerical methods and constituent models. For the reason that studying SSI is complicated in the field or experimentally, therefore, vigorous numerical modeling analysis is an excellent choice for the purpose of engineering design [9]. SSI is the interrelation among the vibratory characteristics of the superstructure, the foundation and the underlying soil surrounding the foundation. Kinematic and inertial interactions are two fundamental mechanisms that control SSI. The influence of the kinematic interaction is produced by the inability of the foundation to proceed in the same way as the movement of the ground, and the inertial interactions have an impact on the vibrational characteristics of the structure. Due to these inertial forces, shear and base moments are produced at the foundation of the structure, as a result of the relative displacement between the ground and the foundation. In addition, the modal characteristics of the structure are modified by inertial interactions such as the damping factors and the vibrations in the modal frequencies. Simplified analytical and theoretical methods have been used in the literature to study inertial interaction [10-13]. Laboratory and field test data have been validated by numerical modeling for the analysis of soil-foundation interaction $[14,15]$. Alternatively, many studies have been executed on SSI and considering the nonlinear behavior of the soil and using finite elements in the frequency domain [16] and finite difference methods in the time domain [17]. For the development of analytical procedures, numerous laboratory and field studies have been carried out for SSI systems. Stewart et al.(1999) and Kim et al. (2003) [18, 19] conducted an in-depth field study of SSI by using a number of sets of strong movement data recorded in many instrumented 
Halmat Ahmed Awlla et al., International Journal of Emerging Trends in Engineering Research, 8(9), September 2020, 6298 - 6305

buildings were studied, they revealed that the SSI caused a decrease in the natural frequency and an increase in the damping. There was a good agreement between the results of the scaled structures experiment and the theoretical ones. According to Todorovska et al. (2002) [20] the most appropriate way to study the SSI is to conduct large-scale experiments; nevertheless, these types of research are highly-priced and time-consuming. As a consequence, performing experiments on small-scale structures in the laboratory is another choice for studying SSI. FEM or equivalent mass-spring-dashpot models can be used for modeling SSI and the dynamic behavior of foundations. On the other hand, the soil can be modelled using FEM by both the theory of integral equations and Green's functions, by the boundary element method (BEM) [21]. There are generally two concepts that are used to assess SSI, they are the fixed base and the flexible base models. For the implementation of these types of models, a certain number of test data, strong recorded earthquakes and analytical studies were used [22]. Fixed base structures react differently than flexible base systems when subjected to seismic motion. The natural periods are shorter and the damping values are lower for the structures with the fixed base than for those with a flexible base [10, 23]. In recent decades, the linear elastic soil hypothesis was fundamentally used for SSI modeling [7]. Although, there are convenient methods and several different applications that can be used to realistically represent nonlinear and dynamic behaviors. With an up-to-date computer evolution and using FEM analysis, SSI can be simulated with a full 3D scale which can represent more realistic and give more precise results [24-26]. Almost all numerical codes by finite elements carry out analysis in the time domain and allow the application of constitutive laws characterizing the behavior of the soil as linear and nonlinear. There are many commercial software packages available that are capable of doing linear and nonlinear analysis such as ANSYS, ADINA, ABAQUS, DYNAFLOW, however, these programs are not designed for SSI analysis specifically. There are other finite element programs particularly designed for SSI analysis, including FLUSH and SASSI. In addition, GEFDYN is non-linear analysis software specializing in soil-fluid structures [21, 27]. In conventional structural analysis and design procedures, engineers are utilizing the fixed-base concept regardless the type of underneath soil. Despite the SSI laboratory and field tests available in the literature, there are neither full scale not scaled laboratory SSI tests have been performed yet for comparing of the dynamic responses of a fixed-base structure with its prototypes resting on different soil profiles. This article is a numerical study that aimed to examine the accuracy of fixed-base concept when employed as a simplified alternative procedure for the structures resting on different soil profiles under dynamic loading conditions. For this purpose, the dynamic responses of a four-story fixed-base structure were analyzed by using numerical methods and compared to its prototypes, which were embedded in a rock stratum, very dense, stiff and soft soils.

\section{NUMERICAL MODELING}

Several methods have been suggested for considering SSI, among them macro-element modelling [28], 3D elasto-dynamic infinite element [29], equivalent dynamic infinite element [30], cone segments [31], continues mass model [32], perfectly matched discrete layers [33] and plane strain FEM [34]. However it is reported that full 3D nonlinear modelling considering SSI as a most accurate method compared with them $[35,36]$ the only technique that remains valid for all types of structural problems is full $3 \mathrm{D}$ analysis which includes complex geometry, different loading cases, material nonlinearities and contact conditions. In this research, the SAP2000 software package was used throughout the study. The program is known as a user-friendly interface and the most common finite element software in the structural engineering community. For considering the inelasticity of the frame structures, two main formulations are available, the distributed plasticity method and the lumped plasticity method, in the modeling of the first type, two non-linear rotation springs of zero length are connected by an elastic beam/column element (line element), that the spring calculates the non-linearity during loading. The second one discretizes the sections into fibers and the length into integration points, it is so called fiber element modeling [37, 38]. However, the non-linear analysis is not part of the present study and numerical cases were analyzed under a linear dynamic loading because the aim of the study is to evaluate and compare the dynamic responses of the fixed base model with the models in which SSI is considered. Six different soil profiles (Hard rock, Rock, Very dense, Stiff, Soft and Very soft) have been defined in the well-known seismic codes among them Uniform Building Code (UBC), American Society of Civil Engineers (ASCE) and International Building Code (IBC). According to the codes, any data are not available for the sixth one since this soil profile does need a detailed specific site investigation, however for the other soil profiles a range limitation for shear wave velocity (Vs), standard penetration test and undrained shear strength were provided. For the current research (Rock, Very dense, Stiff and Soft) soil profiles are studied for considering SSI into account. Shear wave velocity (Vs) for each soil profile was determined by using the tables of the mentioned codes. Now if the density of soil is known, then shear modulus $\left(\mathrm{G}_{\mathrm{s}}\right)$ can be calculated using equation (1). The densities of all soil profiles were defined according to [39, 40], Shear wave velocity and calculated shear modulus for different soil profiles are presented in Table 1.

Table 1: Density, shear wave velocity and shear modulus for different soil profiles

\begin{tabular}{|c|c|c|c|}
\hline $\begin{array}{c}\text { Soil } \\
\text { profiles }\end{array}$ & $\begin{array}{c}\text { DensityK } \\
\mathbf{g} / \mathbf{m}^{\mathbf{3}}\end{array}$ & $\begin{array}{c}\text { Shear wave } \\
\text { velocity-Vs (m/s) }\end{array}$ & $\begin{array}{c}\text { Shear } \\
\text { Modulus-MPa }\end{array}$ \\
\hline Rock & 2064 & 1130 & 2635.5 \\
\hline V-dense & 1950 & 560 & 611.5 \\
\hline Stiff & 1864 & 270 & 135.9 \\
\hline Soft & 1667 & 170 & 48.2 \\
\hline
\end{tabular}


According to many references, among them [41-44] the value of Poisson's ratio ranging between ( 0.1 to 0.3$)$ for Rock and Very dense soils, however for Soft and Stiff soils this value varies between (0.2 to 0.4$)$. Thus, for each soil profile five numerical cases (Case-1 to Case-5) were constructed. By relating Poisson's ratio, shear modulus and equation (2), modulus of elasticity was calculated for each soil profile and refined in Table 2.

$$
\begin{aligned}
& V_{s}=\sqrt{\frac{G_{s}}{\rho}} \\
& G_{g}=\frac{E_{g}}{2(1+v)}
\end{aligned}
$$

For rock and Very dense soils (Case-1, Case-2, Case-3, Case- 4 and Case-5) were modeled for Poisson's ratios $(v=0.10, v=0.15, v=0.20, v=0.25$ and $v=0.30)$, on the other hand for Stiff and Soft soils (Case-1, Case-2, Case-3, Case-4 and Case-5) were created for Poisson's ratios $(v=0.20$, $v=0.25, v=0.30, v=0.35$ and $v=0.40$ ), respectively.

Table 2 :Modulus of elasticity in (MPa) for different soil profiles and Poisson's ratios

\begin{tabular}{|c|c|c|c|c|c|c|c|}
\hline $\begin{array}{c}\text { Poisso } \\
\text { n ratio }\end{array}$ & 0.10 & 0.15 & 0.20 & 0.25 & 0.30 & 0.35 & 0.40 \\
\hline Rock & 5798 & 6061 & 6325 & 6589 & 6852 & --- & --- \\
\hline $\begin{array}{c}\text { Very } \\
\text { dense }\end{array}$ & 1345 & 1407 & 1467 & 1529 & 1590 & --- & --- \\
\hline Stiff & --- & --- & 326 & 340 & 353 & 367 & 381 \\
\hline Soft & --- & --- & 116 & 120 & 125 & 130 & 135 \\
\hline
\end{tabular}

\subsection{Description of the structure}

A four-story steel structure with two bays in each orthogonal direction on a big soil medium was modelled using SAP2000 finite element code Figure 1. The center to center length of each bay and story heights are defined as $4 \mathrm{~m}$ and $3 \mathrm{~m}$, respectively. W12X106 and W12X72 steel standard sections were utilized for modeling the columns of the first two lower and the other two upper stories, respectively. Beams were modelled with W12X50 steel sections. A total load of 1.5 ton $/ \mathrm{m}^{2}$ was assigned to the floors as addition load to the self-weight of the structure. $2 \times 2 \times 0.5 \mathrm{~m}$ reinforced concrete single footing was used. The big soil medium was modelled by means of eight-node brick solid finite elements that each node has three translational degrees of freedom. The total number of 33440 solid finite elements was used for modeling the underneath soil. The fixed base boundary was assigned to the base finite element meshes of the model while the roller boundary was used for the vertical faces based on the previous suggestions $[9,36,45]$. It was concluded from the previous studies $[2,25,30,36,46,47]$ that the dimensions of the substructure mostly case dependent, it's better to extend substructure sides as greater as possible to eliminate the possible boundary effects but in any case not less than the half of length and width of the base dimensions of the structure. To avoid any influence of the outer boundary, the model is extended with dimensions of (160x80x32 m).

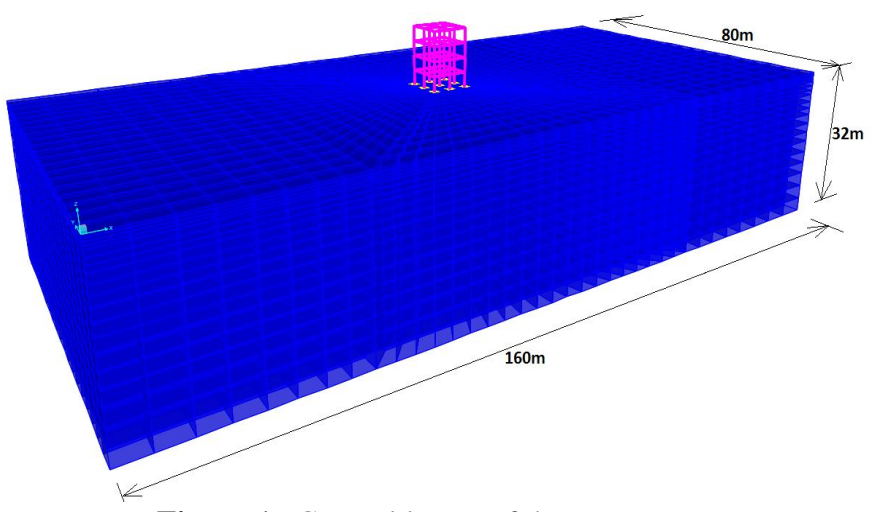

Figure 1 : General layout of the structure.

Each numerical case was analyzed under Elcentro time history acceleration loading, the curve is shown in Figure 2. Dynamic responses in terms of time history base shears and top story displacements are presented in Figure 3 and Figure 4.

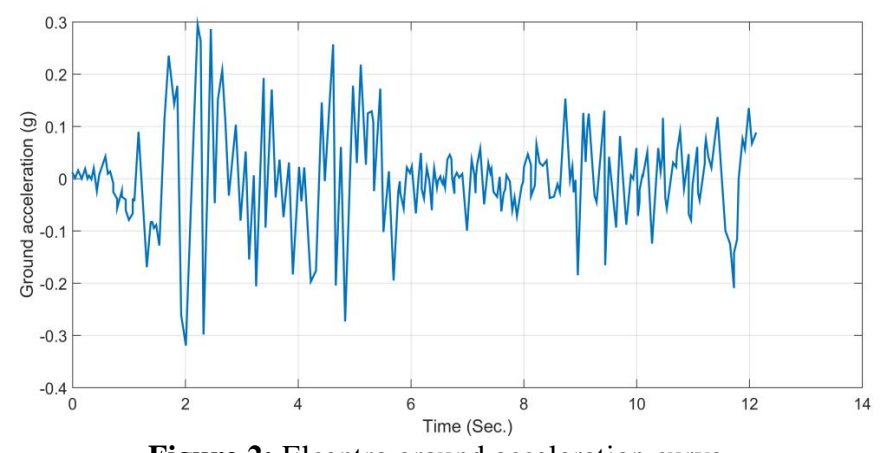

Figure 2: Elcentro ground acceleration curve.

\section{RESULTS AND DISCUSSION}

After performing the linear time history analysis for the fixed-base and all the other soil-structure interaction numerical cases, the obtained dynamic responses results in terms of time history base shear and top story displacements from the numerical analyses for the four soil type profiles are presented in Figure 3 and Figure 4. The maximum base shear and top story displacements were calculated and refined in Figure 5 and Figure 6 . The scale of the dynamic responses affected by the embedment of different soils is calculated by making a comparison study, in the study the responses of the five numerical cases for each soil were compared with those on a fixed base, the differences in percentage between the responses of each numerical case and a fixed base were calculated. 
Halmat Ahmed Awlla et al., International Journal of Emerging Trends in Engineering Research, 8(9), September 2020, 6298 - 6305

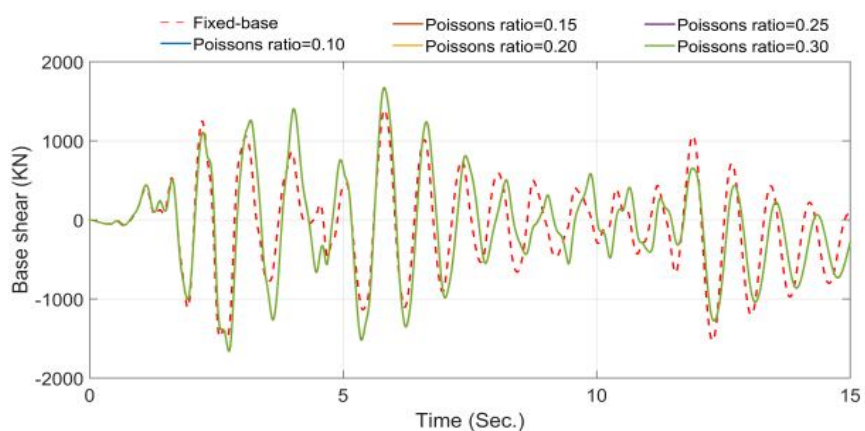

a) Rock soil

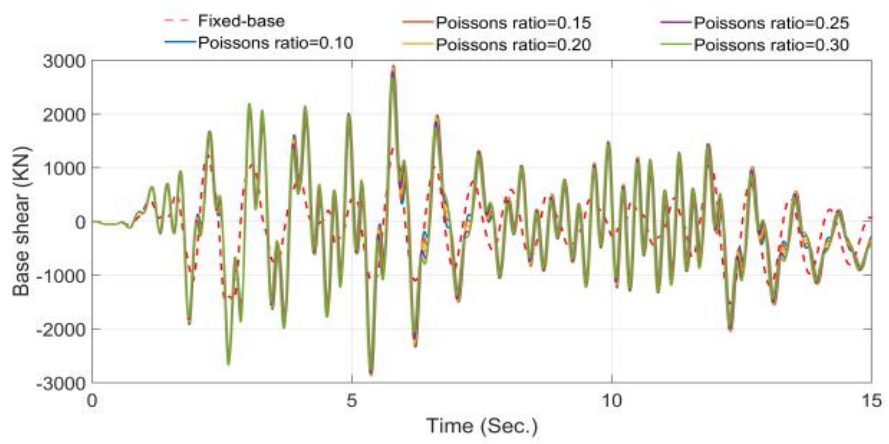

b) Very dense soil

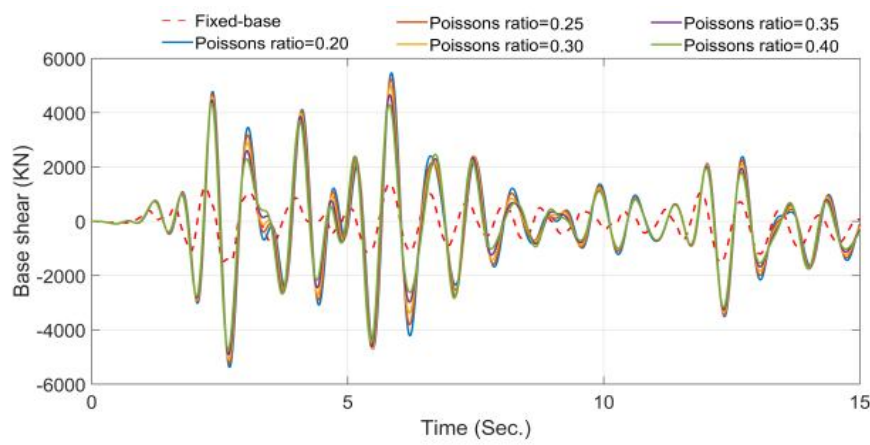

c) Stiff soil

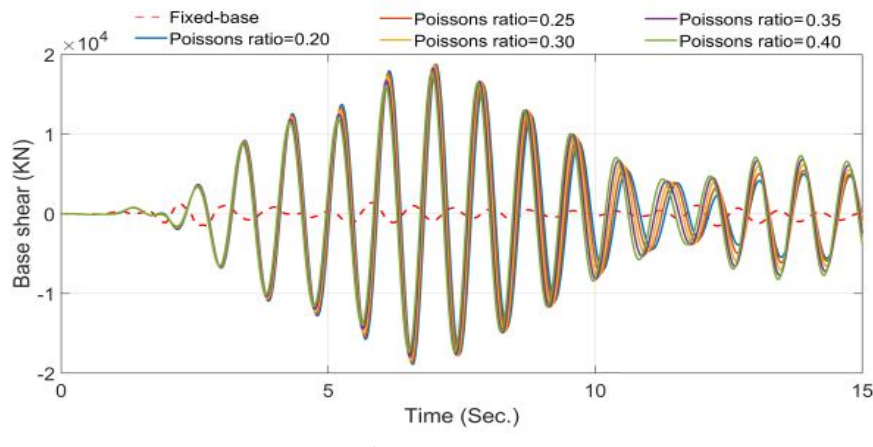

d) Soft soil

Figure 3 Base shear $(\mathrm{KN})$ for different soil profiles and different Poisson's ratios.

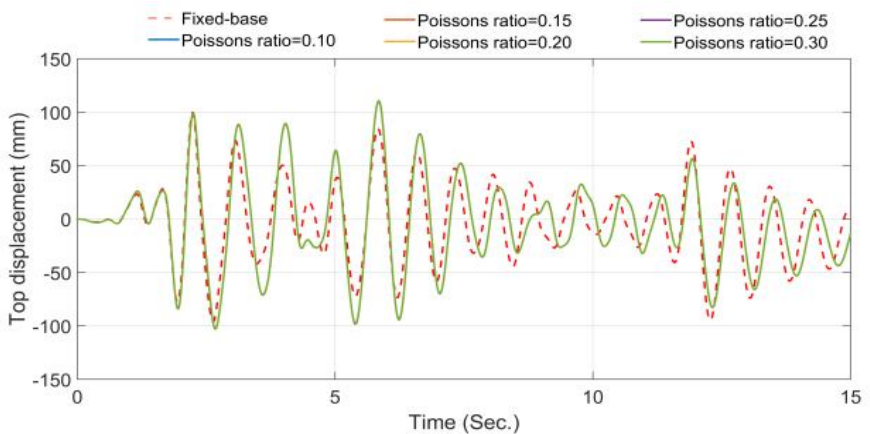

a) Rock soil

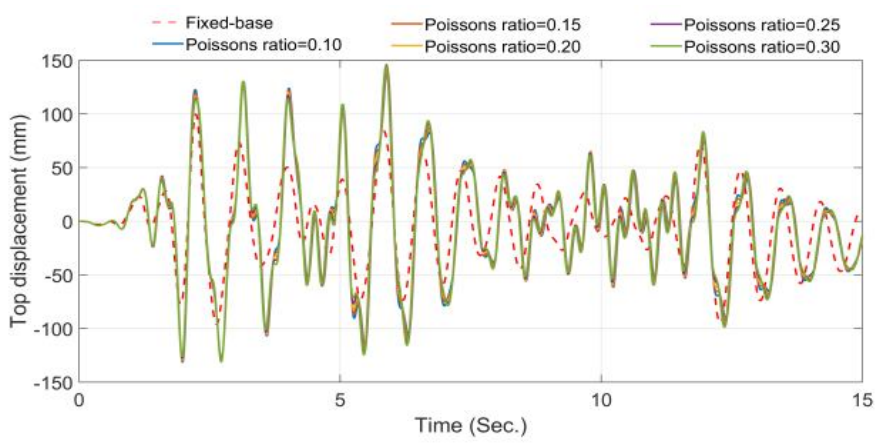

b) Very dense soil

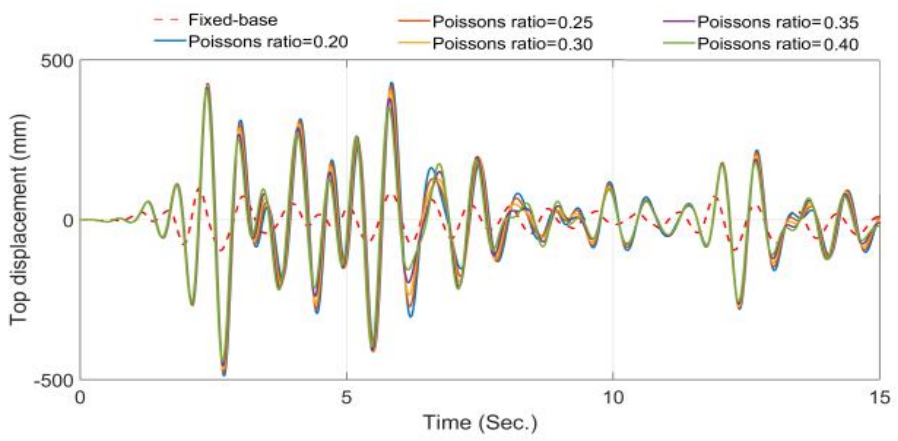

c) Stiff soil

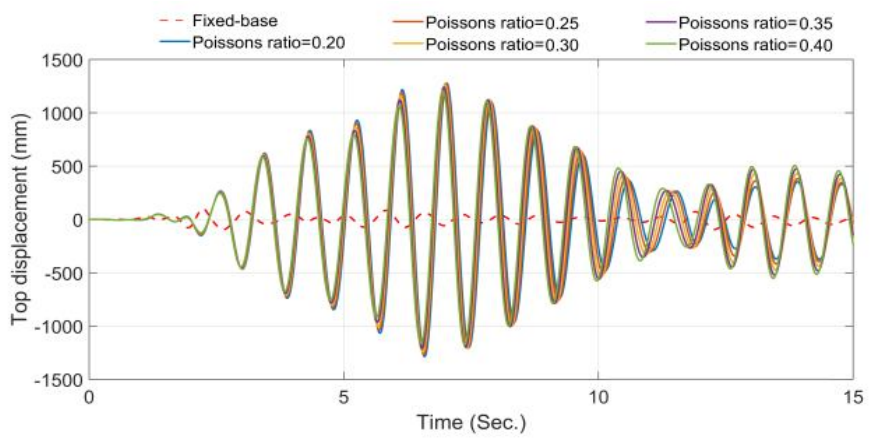

d) Soft soil

Figure 4 :Top story displacement $(\mathrm{mm})$ for different soil profiles and different Poisson's ratios. 


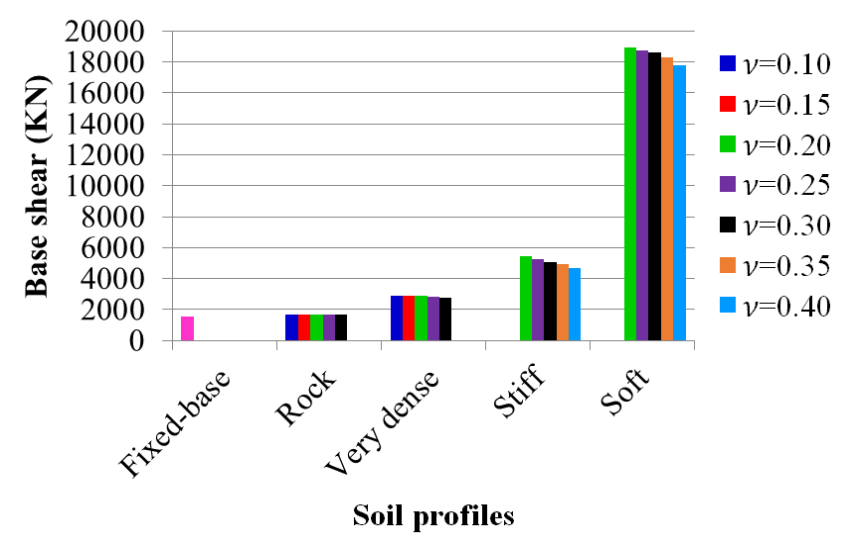

Figure 5: Maximum base shear in $(\mathrm{KN})$ of fixed-base and SSI models for different Poisson's ratio values

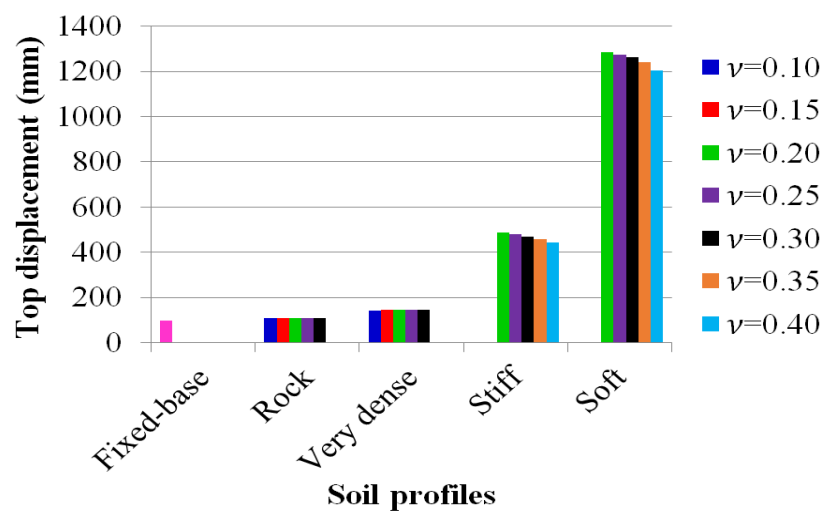

Figure 6: Maximum top story displacement in (mm) of fixed-base and SSI models for different Poisson's ratio values

From the data presented in Figure 5 and Figure 6, maximum base shear and top story displacements from all five numerical cases for each soil profile were determined and presented in Table 3. And the difference ratios of the maximum base shear and top story displacement between each soil profile numerical case and fixed-base one were calculated and presented in Figure 7.

Table 3: Maximum base shear and top story displacement for fixed-base and all soil profiles

\begin{tabular}{|c|c|c|c|c|}
\hline $\begin{array}{c}\text { Soil } \\
\text { profile }\end{array}$ & $\begin{array}{c}\text { Max. base } \\
\text { shear }\end{array}$ & $\begin{array}{c}\text { Fixed-base } \\
\text { base shear }\end{array}$ & $\begin{array}{c}\text { Max. top } \\
\text { disp. }\end{array}$ & $\begin{array}{c}\text { Fixed-base } \\
\text { top disp. }\end{array}$ \\
\hline Rock & 1672.98 & \multirow{2}{*}{1529.8} & 110.49 & \multirow{2}{*}{99.67} \\
\cline { 1 - 1 } $\begin{array}{c}\text { Very } \\
\text { dense }\end{array}$ & 2910.50 & & 145.88 & \\
\hline Stiff & 5465.2 & & \\
\cline { 1 - 1 } Soft & 18909.3 & & 488.51 & \\
& & 1286.1 & \\
\hline
\end{tabular}

The obtained base shear and top story displacement results for Rock soil profile are presented in Figure 3-a) and Figure 4-a) respectively. According to the performed comparison study, it's been observed that the structures embedded by Rock soil profile, the ratio of differences between the SSI numerical cases and fixed-base one for base shear were not exceed $9 \%$, and this ratio for top story displacements were not greater than $11 \%$. Thus, it can be concluded that fixed-base concept can sufficiently and reasonably predict the responses of structures rested on rock soils under dynamic loading.

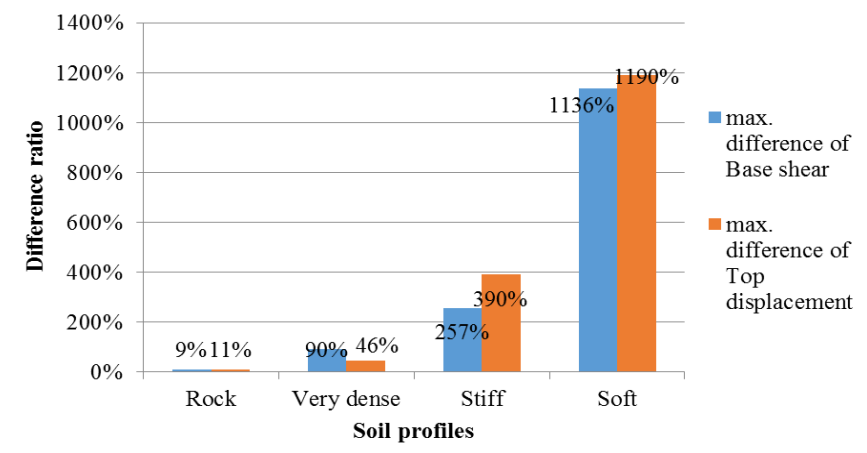

Figure 7 : Maximum percentage difference ratio of base shear and top story displacement between fixed-base and all soil profiles

The calculated base shear and top story displacement results for Very dense, Stiff and Soft soil profiles are also presented in Figure 3-b), c), d) and Figure 4-b) c), d). According to the performed comparison study, it's been observed that the ratio of differences between SSI numerical cases and fixed-base one for base shear were about $90 \%, 257 \%$ and $1136 \%$, on the other side these deviation ratios for top story displacements were found as $46 \%, 390 \%$ and $1190 \%$ for the structures that were embedded by Very dense, stiff and soft soils, respectively. Thus according to the results of the current study, it can be concluded that fixed-base concept underestimates the responses of structures rested on these types of soil profiles under dynamic loading. The results of the current study show that SSI has significant effects on the responses of structures resting on different soil profiles under dynamic loading. When the dynamic responses of the fixed-base model compared to the SSI cases, maximum responses values occurred in soft soil profile and these values decrease towards Rock soil conditions. It's because of the fact that Soft soils has less stiffness when compared to the harder and rock soils, on the other hand Soft soils are highly compressible because of the large percentage of void ratios in it. As discussed previously, good agreement was seen between the results of fixed-base and Rock soil numerical cases, while for the other soil profiles this agreement was not found. Since the deflections and total base shear are increased for the Medium and Soft soils compared to the Rocky soil, this leads to overstress and subsequently failure in the structural elements. For avoiding situations like that, the provisions of the building codes should be considered into account in the professional engineering designs. As in ASCE 7-16 in the section 11.8.3 point(4) selection of appropriate foundation type and depths (for example pile foundation), selection of appropriate structural systems to accommodate anticipated displacements and forces (for example adding bracing and shear walls to the structural system), ground stabilization (ground improvement), or any combination of these measures. 
Halmat Ahmed Awlla et al., International Journal of Emerging Trends in Engineering Research, 8(9), September 2020, 6298 - 6305

\section{CONCLUSION}

In this study, the accuracy and the effect of the fixed base concept on the dynamic responses of a steel structure were studied. For this purpose, dynamic responses in terms of base shear and top story displacements of a four-story steel structure were examined. The structure rested on a big soil medium that was numerically modelled in a full 3D manner using solid finite elements, four different soil profiles in the well-known seismic codes were defined (Rock, Very dense, Stiff and Soft soils). After conducting dynamic analysis, a comparison was made between the dynamic responses of the fixed base structure with structures rested on different types of the soil profile and the followings conclusions can be drawn:

- According to the results of the analysis, it was observed that the base shear and the top displacements of the fixed base structure are almost the same with the structure resting on the rocky soil, but underestimated comparing to remaining soil profiles.

- The maximum difference ratio of base shear is $9 \%$ and for top story displacement is about $11 \%$, between the fixed-base numerical case and the SSI models for rock soil profiles. It means that fixed-base concept can sufficiently predict the dynamic responses of this type of structures.

- The results of this study revealed that the ratios of difference of dynamic responses are high between the fixed-base numerical case and the SSI numerical cases for very dense, stiff and soft soils. It can be concluded that the structures embedded by these soil profiles cannot be idealized as fixed-base and the SSI should be considered into account.

- For future research, the mat foundation can be investigated so as to study the dynamic responses of structures on the same soil profiles and comparing with idealized fixed-base models. This hypothesis is expected to present better agreement between fixed-base and SSI models.

According to the analysis results of the current study it can be inferred that SSI has significant effects on the dynamic responses of structures. In addition, further studies on the effect of soil structure interaction to dynamic responses of structures are recommended for generalization of the results.

\section{REFERENCES}

1. Betti, R., A.M. Abdel-Ghaffar, and A.S. Niazy, Kinematic soil-structure interaction for long-span cable-supported bridges. Earthquake engineering \& structural dynamics, 1993. 22(5): p. 415-430 DOI: https://doi.org/10.1002/eqe.4290220505.

2. Tabatabaiefar, S.H.R., B. Fatahi, and B. Samali, Seismic behavior of building frames considering dynamic soil-structure interaction. International Journal of Geomechanics, 2013. 13(4): p. 409-420 DOI: https://doi.org/10.1061/(ASCE)GM.1943-5622.000023 1.
3. O.T, C., et al., Strengthening Technologies of Different Types of Foundations in Buildings. International Journal of Emerging Trends in Engineering Research, $2020 . \quad 8(6)$ DOI: https://doi.org/10.30534/ijeter/2020/22862020.

4. Ghandil, M. and F. Behnamfar, Ductility demands of MRF structures on soft soils considering soil-structure interaction. Soil Dynamics and Earthquake Engineering, 2017. 92: p. 203-214 DOI: http://dx.doi.org/10.1016/j.soildyn.2016.09.051.

5. Güllü, $H$. and M. Pala, On the resonance effect by dynamic soil-structure interaction: a revelation study. Natural hazards, 2014. 72(2): p. 827-847 DOI: https://doi.org/10.1007/s11069-014-1039-1.

6. Tongaonkar, N.P. and R.S. Jangid, Seismic response of isolated bridges with soil-structure interaction. Soil Dynamics and Earthquake Engineering, 2003. 23(4): p. 287-302 DOI: https://doi.org/10.1016/S0267-7261(03)00020-4.

7. Ouanani, M. and B. Tiliouine, Effects of foundation soil stiffness on the 3-D modal characteristics and seismic response of a highway bridge. KSCE Journal of Civil Engineering, 2014. 19(4): p. 1009-1023 DOI: https://doi.org/10.1007/s12205-013-0435-5.

8. Jaenab, S., Comparison of Strength and Performance Based Designs for Buildings of Different Heights and Area Width. International Journal of Emerging Trends in Engineering Research, $2020.8(6)$ DOI: https://doi.org/10.30534/ijeter/2020/14862020.

9. Torabi, H. and M.T. Rayhani, Three dimensional finite element modeling of seismic soil-structure interaction in soft soil. Computers and Geotechnics, 2014. 60: $\quad$ p. $\quad 9-19$ DOI: https://doi.org/10.1016/j.compgeo.2014.03.014.

10. Veletsos, A.S. and J.W. Meek, Dynamic behaviour of building-foundation systems. Earthquake Engineering and Structural Dynamics, 1974. 3(2): p. 121-138 DOI: https://doi.org/10.1002/eqe.4290030203.

11. Mita, A. and E. Luco, Dynamic response of a square foundation embedded in an elastic half-space. Soil Dynamics and Earthquake Engineering, 1989. 8(2): p. 54-67 DOI: https://doi.org/10.1016/S0267-7261(89)80013-2.

12. Gazetas, G., Formulas and Charts for Impedances of Surface and Embedded Foundations. Journal of Geotechnical Engineering, 1991. 117(9): p. 1363-1381 DOI:

https://doi.org/10.1061/(ASCE)0733-9410(1991)117:9 (1363).

13. Nguyen, V.-V., T.-K. Pham, and H.-B. Tran, Evaluation of Response Modification Factor of Multiple Story Steel Buildings. International Journal of Emerging Trends in Engineering Research, 2020. $8(4)$

DOI: https://doi.org/10.30534/ijeter/2020/66842020.

14. Barros, F.C.P.d. and J.E. Luco, Identification of foundation impedance functions and soil properties 
Halmat Ahmed Awlla et al., International Journal of Emerging Trends in Engineering Research, 8(9), September 2020, 6298 - 6305

from vibration tests of the Hualien containment model. Soil Dynamics and Earthquake Engineering, 1995. 14(4): p. 229-248 DOI: https://doi.org/10.1016/0267-7261(94)00046-J.

15. Tileylioglu, S., J.P. Stewart, and R.L. Nigbor, Dynamic Stiffness and Damping of a Shallow Foundation from Forced Vibration of a Field Test Structure. Journal of Geotechnical and Geoenvironmental Engineering, 2011. 137(4): p. 344-353 DOI: https://doi.org/10.1061/(ASCE)GT.1943-5606.000043 0 .

16. Kim, Y.-S. and J.M. Roesset, Effect of Nonlinear Soil Behavior on Inelastic Seismic Response of a Structure. International Journal of Geomechanics, 2004. 4(2): p. 104-114 DOI: https://doi.org/10.1061/(ASCE)1532-3641(2004)4:2(1 04).

17. Rayhani, M.H. and M.H.E. Naggar, Numerical Modeling of Seismic Response of Rigid Foundation on Soft Soil. International Journal of Geomechanics, 2008. 8(6): p. 336-346 DOI: https://doi.org/10.1061/(ASCE)1532-3641(2008)8:6(3 36).

18. Stewart, J.P., R.B. Seed, and G.L. Fenves, Seismic Soil-Structure Interaction in Buildings. II: Empirical Findings. Journal of Geotechnical and Geoenvironmental Engineering, 1999. 125(1): p. 38-48 DOI:

https://doi.org/10.1061/(ASCE)1090-0241(1999)125:1 (38).

19. Kim, S. and J.P. Stewart, Kinematic soil-structure interaction from strong motion recordings. Journal of Geotechnical and Geoenvironmental Engineering, 2003. 129(4): p. 323-335 DOI: https://doi.org/10.1061/(ASCE)1090-0241(2003)129:4 (323).

20. Todorovska, M.I., Full-Scale Experimental Studies Of Soil-Structure Interaction. ISET Journal of Earthquake Technology, 2002. 39(3): p. 139-165 Available from: https://iset.org.in/public/publications/72866_Paper\%20 No.\%20422\%20(1)n.pdf.

21. Pitilakis, D., et al., Numerical simulation of dynamic soil-structure interaction in shaking table testing Soil Dynamics and Earthquake Engineering, 2008. 28(6): $\quad$ p. $453-467$ DOI: https://doi.org/10.1016/j.soildyn.2007.07.011.

22. Şafak, E., Detection and Identification of Soil-Structure Interaction in Buildings from Vibration Recordings. Journal of Structural Engineering, 1995. 121(5): p. 899-906 DOI: https://doi.org/10.1061/(ASCE)0733-9445(1995)121:5 (899).

23. Bielak, J., Dynamic behaviour of structures with embedded foundations. Earthquake Engineering and Structural Dynamics, 1974. 3(3): p. 259-274 DOI: https://doi.org/10.1002/eqe.4290030305.
24. Cakir, T., Evaluation of the effect of earthquake frequency content on seismic behavior of cantilever retaining wall including soil-structure interaction. Soil Dynamics and Earthquake Engineering, 2013. 45: p. 96-111 DOI: https://doi.org/10.1016/j.soildyn.2012.11.008.

25. Park, J.H., J.F. Choo, and J.-R. Cho, Dynamic soil-structure interaction analysis for complex soil profiles using unaligned mesh generation and nonlinear modeling approach. KSCE Journal of Civil Engineering, 2013. 17(4): p. 753-762 DOI: https://doi.org/10.1007/s12205-013-0135-1.

26. Livaoglu, R., The numerical and empirical evaluation of chimneys considering soil structure interaction and high-temperature effects. Soil Dynamics and Earthquake Engineering, 2014. 66: p. 178-190 DOI: https://doi.org/10.1016/j.soildyn.2014.07.006.

27. O.T., C., et al., Study of the macrostructure of steel (macroanalysis). International Journal of Emerging Trends in Engineering Research, 2020. 8(7) DOI: https://doi.org/10.30534/ijeter/2020/1338720200.

28. Grange, S., P. Kotronis, and J. Mazars, A macro-element to simulate 3D soil-structure interaction considering plasticity and uplift. International Journal of Solids and Structures, 2009. 46(20): p. 3651-3663 DOI: https://doi.org/10.1016/j.ijsolstr.2009.06.015.

29. Seo, C.-G., C.-B. Yun, and J.-M. Kim, Three-dimensional frequency-dependent infinite elements for soil-structure interaction. Engineering Structures, 2007. 29(11): p. 3106-3120 DOI: https://doi.org/10.1016/j.engstruct.2007.02.006.

30. Su, J. and Y. Wang, Equivalent dynamic infinite element for soil-structure interaction. Finite Elements in Analysis and Design, 2013. 63: p. 1-7 DOI: https://doi.org/10.1016/j.finel.2012.08.006.

31. Wolf, V.P. and M. Preisig, Dynamic stiffness of foundation embedded in layered halfspace based on wave propagation in cones. Earthquake engineering and structural dynamics, 2003. 32(7): p. 1075-1098 DOI: https://doi.org/10.1002/eqe.263.

32. Chouw, N. and H. Hao, Significance of SSI and nonuniform near-fault ground motions in bridge response I: Effect on response with conventional expansion joint. Engineering Structures, 2008. 30(1): p. 141-153 DOI: https://doi.org/10.1016/j.engstruct.2007.03.002.

33. Lee, J.H., J.K. Kim, and J.H. Kim, Nonlinear analysis of soil-structure interaction using perfectly matched discrete layers. Computers \& Structures, 2014. 142: p. 28-44

DOI: https://doi.org/10.1016/j.compstruc.2014.06.002.

34. Ellis, E.A. and S.M. Springman, Modelling of soil-structure interaction for a piled bridge abutment in plane strain FEM analyses. Computers and Geotechnics, 2001. 28(2): p. 79-98 DOI: https://doi.org/10.1016/S0266-352X(00)00025-2. 
35. Kampitsis, A.E., et al., Seismic soil-pile-structure kinematic and inertial interaction-A new beam approach. Soil Dynamics and Earthquake Engineering, 2013. 55: p. 211-224 DOI: https://doi.org/10.1016/j.soildyn.2013.09.023.

36. Yoo, C., Interaction between tunneling and bridge foundation - A 3D numerical investigation. Computers and Geotechnics, 2013. 49: p. 70-78 DOI: https://doi.org/10.1016/j.compgeo.2012.11.005.

37. Karaton, M. and H.A. Awla, Numerical investigation of the effect on ultimate loading capacity of different longitudinal reinforcement ratios of a $\mathrm{RC}$ portal frame. Journal of Structural Engineering \& Applied Mechanics, 2018. 1(3): p. 147-154 DOI: https://doi.org/10.31462/jseam.2018.03147154.

38. Ahmed, H., Investigation of a reverse engineering method for determination of material properties of damaged or collapsed reinforced concrete building. Msc thesis. 2019, Turkey: Firat University, Faculty of Engineering, Civil Engineering Department. https://tez.yok.gov.tr/UlusalTezMerkezi/tezDetay.jsp?i $\mathrm{d}=$ oTG-SJC-ovATsQtvTqqs_g\&no=_qMBvwpGFpNmp63emidog.

39. Look, B.G., Handbook of geotechnical investigation and design tables. 2014: CRC Press.

40. Hökelekli, E. and A. Al-Helwani, Effect of soil properties on the seismic damage assessment of historical masonry minaret-soil interaction systems. The Structural Design of Tall and Special Buildings, 2020. 29(2): p. e1694 DOI: https://doi.org/10.1002/tal.1694.

41. Kaniraj, S.R., Design aids in soil mechanics and foundation engineering. 1988: Tata McGraw-Hill.

42. Bowles, L., Foundation analysis and design. 1996: McGraw-Hill.

43. Terzaghi, K., R.B. Peck, and G. Mesri, Soil mechanics in engineering practice. 1996: John Wiley \& Sons.

44. Ameratunga, J., N. Sivakugan, and B.M. Das, Correlations of soil and rock properties in geotechnical engineering. 2016: Springer DOI: https://doi.org/10.1007/978-81-322-2629-1.

45. Kramer, S.L., Geotechnical earthquake engineering. 1996: Upper Saddle River, N.J Prentice Hall 1996.

46. Livaoglu, R. and A. Dogangun, Effect of foundation embedment on seismic behavior of elevated tanks considering fluid-structure-soil interaction. Soil Dynamics and Earthquake Engineering, 2007. 27(9): p. 855-863

DOI: https://doi.org/10.1016/j.soildyn.2007.01.008.

47. Güllü, H. and H.S. Jaf, Full 3D nonlinear time history analysis of dynamic soil-structure interaction for a historical masonry arch bridge. Environmental Earth Sciences, 2016. 75(21): p. 1421 DOI: https://doi.org/10.1007/s12665-016-6230-0. 